\title{
Thermal, Morphological, and Biodegradability Properties of Bioplastic Fertilizer Composites Made of Oil Palm Biomass, Fertilizer, and Poly(hydroxybutyrate-co-valerate)
}

\author{
A. S. Harmaen, ${ }^{1}$ A. Khalina, ${ }^{2}$ H. Mohd Ali, ${ }^{3}$ and I. Nor Azowa ${ }^{4}$ \\ ${ }^{1}$ Institute of Tropical Forestry and Forest Products, Universiti Putra Malaysia (UPM), 43400 Serdang, Selangor, Malaysia \\ ${ }^{2}$ Faculty of Engineering, Universiti Putra Malaysia (UPM), 43400 Serdang, Selangor, Malaysia \\ ${ }^{3}$ Faculty of Biotechnology and Biomolecular Sciences, Universiti Putra Malaysia (UPM), 43400 Serdang, Selangor, Malaysia \\ ${ }^{4}$ Faculty of Science, Universiti Putra Malaysia (UPM), 43400 Serdang, Selangor, Malaysia
}

Correspondence should be addressed to A. S. Harmaen; harmaen@upm.edu.my

Received 5 August 2015; Revised 20 December 2015; Accepted 21 January 2016

Academic Editor: Shiv Shankar

Copyright (C) 2016 A. S. Harmaen et al. This is an open access article distributed under the Creative Commons Attribution License, which permits unrestricted use, distribution, and reproduction in any medium, provided the original work is properly cited.

\begin{abstract}
Slow-release bioplastic fertilizer $(\mathrm{BpF})$ composites were developed by processing oil palm empty fruit bunch (EFB), fertilizer, and poly(hydroxybutyrate-co-valerate) (PHBv) using extrusion techniques with controlled formulation and temperature. The temperature was kept at $150^{\circ} \mathrm{C}$ for 3 to 5 min during processing using twin-screw extruder. The PHBv lost weight gradually with the increasing temperature and its thermal degradation occurred initially at $263.4^{\circ} \mathrm{C}$ and reached the maximum at $300.7^{\circ} \mathrm{C}$. Scanning electron microscope (SEM) images showed that the bonding of all composites created small gaps between matrices polymer and fiber because the hydrophilic characteristic of EFB fibers weakened the interfacial bonding. PHBv/EFB/NPKC2 showed faster biodegradation over $\mathrm{PHBv} / \mathrm{NPKC1}$ and $\mathrm{PHBv} / \mathrm{NPKC} 2$, which was $99.35 \%$ compared to $68.66 \%$ and $90.28 \%$, respectively.
\end{abstract}

\section{Introduction}

Poly(3-hydroxybutyrate-co-3-hydroxyvalerate) commercially known as Biopol ${ }^{\mathrm{TM}}$ is a derivative of poly(3-hydroxybutyrate) (PHB). PHB has been widely studied as biomedical and biodegradable materials. One of the main hurdles in its commercial applications is the postprocessing embrittlement [1]. Some researchers claimed that the embrittlement is not related to its physical aging but actually caused by secondary crystallization during storage [2-4] where a low temperature melting peak of $75^{\circ} \mathrm{C}$ appears.

The use of bioplastic fertilizers $(\mathrm{BpF})$ in agriculture and horticultural industry has been going on for decades. It is considered as an advanced approach within the slow-release fertilizers (SRF), which play an important role in efficiently delivering the nutrients for plant uptake while controlling the longevity of the product. Most of the SRF used in agriculture industry utilize this type of SRF [5]. Compared to traditional water-soluble fertilizers used in fertigation, $\mathrm{BpF}$ may only require a single application to supply enough nutrients for the plants for an extended period, hence the lower labour costs needed to apply fertilizers. Furthermore, BpF is also often applied together within the media to grow the seedlings.

Uncontrolled or excessive use of fertilizers leads to huge economic losses of resources, apart from being the main cause of environmental pollution [6,7]. Therefore, using SRF can help solve these issues [8-10]. SRF has the ability to release nutrients at a predetermined time and rate to suit the plant uptake at different growth stages [11]. The rate and time of nutrient release are optimized by manipulating the physical and/or chemical characteristics of the fertilizer, involving mechanisms such as diffusion, degradation, and hydrolysis [12]. The rate of nutrient dissolution is also coordinated according to the plant requirements. SRF has many advantages against conventional fertilizers. One of them is the ability to allow gradual release of nutrients, which increases the efficiency of nutrient uptake and leads to higher yield [13, 14]. A setback in using polymer coating for SRF is the issue of degradability of the materials used for coating because they will remain in soil after nutrient release. The accumulation 
of these materials will eventually become a bigger issue of environmental pollution. Therefore, many studies have been dedicated to developing biodegradable and environmentally safe polymer coating materials [15-19].

The demand for natural fibers has seen a drastic increase in recent years because they are renewable and environmentally friendly. Natural fibers have high potential as reinforcements in polymer composites and thus they have been extensively studied for this purpose [20]. As fillers, they have many advantages, such as lower cost, light weight, low density, high strength to weight ratio, biodegradability, and better thermal properties and other acceptable specific properties [21].

Various materials have been tested to be used as fertilizer coating, involving different methods such as spouted bed, fluidized bed, and rotating drum. Tennessee Valley Authority (TVA) tried using rotating drum to produce sulphur-coated urea (SCU) [22]. Then, another study reported the use of spouted bed to produce SCU [23]. Ten years after that, a researcher develops a technique modified fluidized bed to coat urea [24]. All the three approaches have been reviewed and studied further by more recent researchers [25-28]. Regardless of the procedures, the quality of SRF and the accuracy of nutrient release time depend on various parameters.

In this study, the extrusion process involved the compounded NPK fertilizer with EFB and biopolymer. Based on the literature review, CRF/SRF available in the market are commonly made of nonbiodegradable plastic/polymer by means of dipping, emulsion, or spraying. The novelty of this study was the use of compounding method in producing SRF, with the incorporation of biodegradable polymer PHBv. The idea was to add the EFB fibers to reinforce the bioplastic fertilizer and produce SRF bioplastic composites. This bioplastic fertilizer $(\mathrm{BpF})$ composite is able to gradually degrade in soil within a shorter period of time compared to conventional fertilizers. In this study, the $\mathrm{BpF}$ composites have to determine degradation in soil burial test. The data on degradation of $\mathrm{BpF}$ composites were analyzed using ANOVA (SAS system analysis).

\section{Materials and Methods}

2.1. Materials. Poly(hydroxybutyrate-co-valerate) (PHBv) under the trade name Biopol, Germany, was supplied by Innovative Pultrusion Sdn. Bhd., Senawang, Negeri Sembilan. The natural fibers used as fillers were oil palm empty fruit bunch (EFB) fibers, which were supplied by Poly Composite Sdn. Bhd., Teluk Intan, Perak. NPKC1 (uncoated) and NPKC2 (coated) fertilizers were supplied by Diversatech Fertilizer Sdn. Bhd, Bangi, Selangor, Malaysia. The average particle sizes of the EFB and fertilizer in granular form were 0.25 to $0.5 \mathrm{~mm}$.

\subsection{Bioplastic Fertilizer (BpF) Composites Formulation and} Compounding Using Extrusion Processing. The compounding of materials in this section was carried out in twin-screw extruder (Micromac, Malaysia) with a $30 \mathrm{~mm}$ screw diameter. Biodegradable plastics $\mathrm{PHBv}$ and oil palm empty fruit bunch and NPK fertilizer were dried at $103 \pm 2^{\circ} \mathrm{C}$ overnight in a drying oven. The materials to be compounded were fed at a
TABLE 1: Formulation of bioplastic fertilizer (BpF) composites compounding.

\begin{tabular}{lccc}
\hline Composites & PHBv (\%) & EFB fibers (\%) & NPK fertilizers (\%) \\
\hline PHBv/NPKC1 & 40 & 0 & 60 \\
PHBv/NPKC2 & 40 & 0 & 60 \\
PHBv/EFB/NPKC1 & 30 & 10 & 60 \\
PHBv/EFB/NPKC2 & 30 & 10 & 60 \\
\hline
\end{tabular}

Note: PHBv (poly(hydroxybutyrate-co-valerate)), NPKC1 (uncoated) and NPKC2 (coated), and EFB (empty fruit bunch).

constant speed into the hopper extruder by means of a screw feed system. The product was bioplastic fertilizer (BpF) composites containing biodegradable plastic, empty fruit bunch, and NPK fertilizer. These components were homogenized in the mixer. The reverse barrel temperature profile from the feed throat to die exit ranged from $145^{\circ} \mathrm{C}$ to $160^{\circ} \mathrm{C}$. The formulation of bioplastic fertilizer $(\mathrm{BpF})$ composites is presented in Table 1. The premix was fed into the main feeder at the speed of $15 \mathrm{rpm}$. The extruder screw speed was $40 \mathrm{rpm}$. The temperature was about $145^{\circ} \mathrm{C}$ for Section I, about $150^{\circ} \mathrm{C}$ for Section II, and about $160^{\circ} \mathrm{C}$ for Section III.

2.3. Thermogravimetric Analysis (TGA). The equipment used in thermogravimetric analysis was TGA Q500, TA Instruments. Ten milligrams of samples was heated under the temperature range from $35^{\circ} \mathrm{C}$ to $600^{\circ} \mathrm{C}$ at the rate of $10^{\circ} \mathrm{C} / \mathrm{min}$. The analysis required nitrogen atmosphere with the flow rate of nitrogen at $20 \mathrm{~mL} / \mathrm{min}$. The weight reduction of samples was recorded and plotted against temperature.

2.4. Differential Scanning Calorimetry Analysis (DSC). The equipment used in DSC analysis was Differential Scanning Calorimeter DSC Q20, TA Instruments. The analysis required argon atmosphere with the flow rate of argon at $50 \mathrm{~mL} / \mathrm{min}$. Ten milligrams of samples was weighted and sealed in an aluminium pan. In the nonisothermal melt-crystallization, the melted samples were cooled to $-20^{\circ} \mathrm{C}$ at a cooling rate of $10^{\circ} \mathrm{C} / \mathrm{min}$ after melting at $200^{\circ} \mathrm{C}$ for $2 \mathrm{~min}$. Subsequently, the crystallized samples were heated to $250^{\circ} \mathrm{C}$ at $10^{\circ} \mathrm{C} / \mathrm{min}$ to determine their melting behavior. In the isothermal meltcrystallization, the samples melted at $200^{\circ} \mathrm{C}$ for 2 min were cooled at a rate of $100^{\circ} \mathrm{C} / \mathrm{min}$ to the desired crystallization temperature $\left(T_{c}\right)$ and allowed to crystallize. Each sample was recorded for its cold crystallization temperature $\left(T_{c}\right)$, glass transition temperature $\left(T_{g}\right)$, and melting temperature $\left(T_{m}\right)$.

2.5. Scanning Electron Microscopy (SEM). Scanning electron microscope (S-3400N, Hitachi, Japan) was used to analyze the surfaces of the fractured samples. At the cathode, the acceleration voltage was set at $15 \mathrm{kV}$. Prior to this, the samples were sputter-coated with gold dust in the coater Emitech K550X (600 s, $35 \mathrm{~mA}, 2 \times 10^{-1}$ bar).

2.6. Biodegradation Test. The BpF composites biodegradation test involved the simulation of natural soil environment in a simple soil burial test. The natural soil was collected earlier and it was made sure that it did not contain any 
TABLE 2: TGA characterisation of pure PHBv, PHBv/NPK, and PHBv/NPK/EFB composites.

\begin{tabular}{lccc}
\hline & \multicolumn{2}{c}{ Degradation temperature $\left({ }^{\circ} \mathrm{C}\right)$} & $T_{\mathrm{FDT}}$ \\
Composites & $T_{\mathrm{IDT}}$ & 285.45 & 41.80 \\
NPKC1 & 76.12 & 372.63 & 40.82 \\
NPKC2 & 76.01 & 342.82 & 23.11 \\
EFB & 251.18 & 300.73 & 0.257 \\
PHBv & 263.44 & 471.76 & 27.00 \\
PHBv/NPKC1 & 268.76 & 495.74 & 29.76 \\
PHBv/NPKC2 & 269.30 & 439.26 & 29.07 \\
PHBv/EFB/NPKC1 & 268.23 & 426.47 & 25.41 \\
PHBv/EFB/NPKC2 & 252.78 & & \\
\hline
\end{tabular}

Notes: $T_{\mathrm{IDT}}$ : initial decomposition temperature; $T_{\mathrm{FDT}}$ : final decomposition temperature.

PHBv (poly(hydroxybutyrate-co-valerate)), NPKC1 (uncoated) and NPKC2 (coated), and EFB (empty fruit bunch).

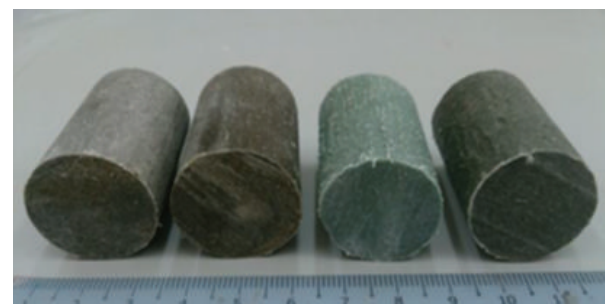

FIgURE 1: Bioplastic fertilizer (BpF) composites.

composting materials or enzyme activity. In this test, 5 replications samples were simply buried in the natural soil and were kept at temperature between $25^{\circ} \mathrm{C}$ and $30^{\circ} \mathrm{C}$, with relative humidity of around $65 \%$. The test spanned for a total of 16 weeks and the samples were recovered every four weeks for analysis. Thus, there were seven degradation stages, starting from Week 0, Week 4, and so on until Week 16. For each stage, the samples recovered were rinsed under running water to get rid of soil residues from the surface. Drying oven with the temperature of $80^{\circ} \mathrm{C}$ was used to completely remove the moisture until a constant dry weight was obtained for each sample. The weight loss after the soil burial test indicated the level of biodegradability of the samples. The calculation of weight loss involved the following equation:

$$
\text { Weight loss }(\%)=\frac{W_{0}-W_{1}}{W_{0}} \times 100,
$$

where $W_{0}$ is the weight before the test while $W_{1}$ is the weight after the test.

\section{Results and Discussion}

3.1. Fabrication of Bioplastic Fertilizer (BpF) Composites. The samples of the BpF composites are shown in Figure 1. After compounding, the samples were extruded from mould and cut to about $30 \mathrm{~mm}$ in length. In this study, the samples of $\mathrm{BpF}$ composites were compounded to achieve homogeneity, with good bonding and dispersion. One of the best methods to obtain good dispersion of fillers in the biopolymer matrix is the twin-screw extrusion technique $[29,30]$. However, the sensitivity of the temperature during compounding processes

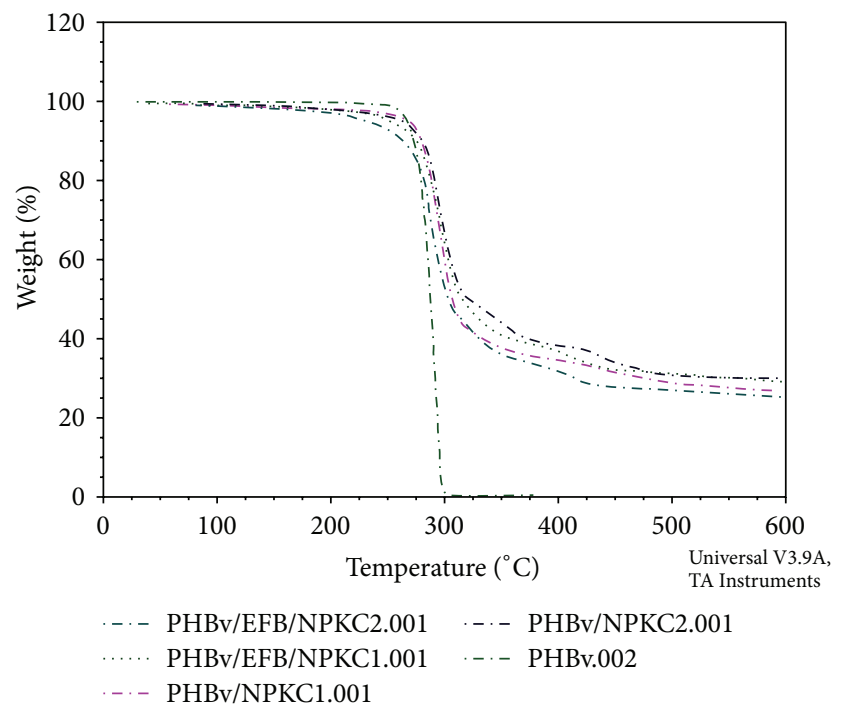

FIGURE 2: TGA thermograms showing the thermal properties of pure $\mathrm{PHBv}, \mathrm{PHBv} / \mathrm{NPK}$, and $\mathrm{PHBv} / \mathrm{EFB} / \mathrm{NPK}$ composites. Note: PHBv (poly(hydroxybutyrate-co-valerate)), NPKC1 (uncoated) and NPKC2 (coated), and EFB (empty fruit bunch).

involving extrusion or injection moulding is limited [31]. The interaction between matrix and fillers (reinforcement) that provide larger surface area improves the mechanical properties as well as the dimensional and thermal stability of the composite $[32,33]$. The process conditions, which determine the dispersion and the adhesion/interaction between the fillers and the matrix, influence the enhancement of the composite material $[34,35]$.

3.2. Thermogravimetric (TGA). Table 2 and Figure 2 show the TGA results and the curves which illustrate the weight loss of pure $\mathrm{PHBv}, \mathrm{EFB}$ fibers, and the $\mathrm{BpF}$ composites under increasing temperature. The loss of weight was directly proportional to the increase in temperature. The thermal degradation started at $263.44^{\circ} \mathrm{C}$ and reached its maximum at $300.73^{\circ} \mathrm{C}$. The pure $\mathrm{PHBv}$ has earlier been reported to have thermal instability beyond $250^{\circ} \mathrm{C}$ [36]. It was also mentioned that the chain scission and hydrolysis that occur 
TABLE 3: DSC characterisation of pure PHBv, PHBv/NPK, and PHBv/NPK/EFB composites.

\begin{tabular}{|c|c|c|c|}
\hline Sample & $T_{c}\left({ }^{\circ} \mathrm{C}\right)$ & $T_{g}\left({ }^{\circ} \mathrm{C}\right)$ & $T_{m}\left({ }^{\circ} \mathrm{C}\right)$ \\
\hline NPKC1 & 200.68 & - & 110.26 \\
\hline NPKC2 & - & 30.19 & 86.29 \\
\hline $\mathrm{EFB}$ & - & - & 76.35 \\
\hline PHBv & 46.58 & 94.21 & 171.69 \\
\hline $\mathrm{PHBv/NPKC1}$ & 41.82 & 87.29 & 166.38 \\
\hline $\mathrm{PHBv/NPKC2}$ & 43.71 & 90.84 & 151.63 \\
\hline $\mathrm{PHBv/EFB/NPKC1}$ & 40.49 & 90.79 & 166.53 \\
\hline $\mathrm{PHBv/EFB/NPKC2}$ & 44.29 & 89.07 & 161.29 \\
\hline
\end{tabular}

Notes: crystallization temperature $\left(T_{c}\right)$, glass transition temperature $\left(T_{g}\right)$, and melting temperature $\left(T_{m}\right)$.

PHBv (poly(hydroxybutyrate-co-valerate)), NPKC1 (uncoated) and NPKC2 (coated), and EFB (empty fruit bunch).

in the degradation process lead to weight loss and crotonic acid formation. The moist environment further catalyzes the hydrolytic degradation. The cumulative thermal degradation $\mathrm{PHBv}$ as the matrix and the EFB fibers as the fillers resulted as the thermal degradation of the biocomposites. The thermal degradation of the composites started at approximately $250^{\circ} \mathrm{C}$ and reached its maximum at $400^{\circ} \mathrm{C}$. The TGA results revealed that the fibers were the final component of the composites that underwent degradation. The maximum thermal degradation of the composite was slightly higher than the pure $\mathrm{PHBv}$. As seen in Figure 2, the degraded PHBv did not show any residue. The residual mass was presented as functions of fiber and fertilizer percentage because the degradation of fiber by heating (pyrolysis) in partial or total absence of oxygen produced char residue. Higher concentration of fertilizer in the composites produced higher char residue, but the residue was expected to be lower than the NPK fertilizer for all composites. The thermal degradation of $\mathrm{PHBv}$ largely involved cis-elimination mechanism and random chain scission with a six-membered ring transition state $[37,38]$. The $\mathrm{PHBv} / \mathrm{EFB} / \mathrm{NPKC} 2$ composite was more stable than $\mathrm{PHBv}$ because it had a higher maximum degradation peak than PHBv. The composite was also found to be more thermally stable than other composites because it required higher initial degradation temperature. Thus the presence of NPK and EFB fiber did not have any degradation effect on PHBv.

3.3. Differential Scanning Calorimetry Analysis (DSC). Table 3 presents the DSC results. The addition of NPK fertilizer and EFB fiber to make the BpF composites reduced the crystallinity of the pure PHBv. The DSC thermograms in Figure 3 show reduced melting temperature and the presence of double melting peaks, which suggested a disrupted arrangement of polymer crystal structures due to the addition of EFB fiber to the PHBv matrix. Past studies have reported the nucleating effect of natural fibers which promotes the formation of transcrystalline structures along fiber surfaces during crystallization from the melt [39]. The disordered crystal growth along the interface of fiber-matrix and their interference on the crystals formation in the bulk probably caused the discontinuities in the matrix crystals and reduced the overall crystallinity of the polymer.

Figure 3 shows the thermograms of pure $\mathrm{PHBv}$ blended with 10 wt.\% EFB fibers and $60 \%$ NPK fertilizer. The details

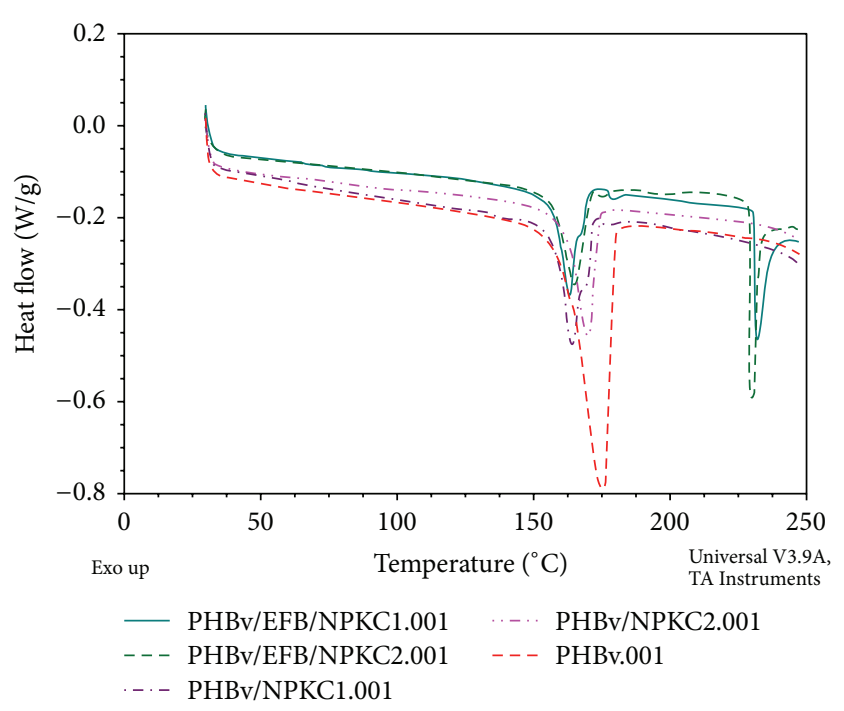

Figure 3: DSC characterisation of pure PHBv, PHBv/NPK, and $\mathrm{PHBv} / \mathrm{NPK} / \mathrm{EFB}$ composites. Note: PHBv (poly(hydroxybutyrateco-valerate)), NPKC1 (uncoated) and NPKC2 (coated), and EFB (empty fruit bunch).

are given in Table 3 where $T_{m}$ is the melting temperature, $T_{g}$ is the glass transition temperature, and $T_{c}$ is the crystallization temperature. The effects of EFB fibers on the crystallinity and nucleation of $\mathrm{PHBv}$ were studied using the nonisothermal DSC. The crystallization of the heterogenous crystal during the heating cycle led to a bimodal endotherm of PHBv [40]. In the presence of fertilizer, the addition of $10 \mathrm{wt} \% \mathrm{EFB}$ fibers increased the crystallization rate, probably because the molecular chains diffused slower through the welldistributed EFB fibers to the nucleus.

3.4. Scanning Electron Microscopy (SEM). Figure 4(a) PHBv/ NPKC1 and (b) PHBv/NPKC2, shows SEM images of the $\mathrm{PHBv}$ and NPK fertilizer composites. These images show some $\mathrm{NPKC} 1$ and $\mathrm{NPKC} 2$ that were well bonded to the matrix. This suggests that the $\mathrm{PHBv} / \mathrm{NPKC1}$ and $\mathrm{PHBv} / \mathrm{NPKC} 2$ composites had better dispersion, wetting, and interfacial adhesion. It was evident that there were weak stress transfer and bad interfacial adhesion between the interfaces of PHBv 
TABLE 4: Weight loss of bioplastic fertilizer $(\mathrm{BpF})$ composites from soil burial test.

\begin{tabular}{|c|c|c|c|c|c|}
\hline \multirow{2}{*}{ Composites } & \multicolumn{5}{|c|}{ Weeks } \\
\hline & 0 & 4 & 8 & 12 & 16 \\
\hline $\mathrm{PHBv/NPKC1}$ & 0 & $50.4 \mathrm{a}(5.78)$ & $55.85 \mathrm{c}(2.28)$ & $60.17 \mathrm{c}(7.70)$ & $68.66 c(2.53)$ \\
\hline $\mathrm{PHBv/NPKC2}$ & 0 & $56.45 \mathrm{a}(12.23)$ & $77.94 b(6.36)$ & $87.78 b(0.98)$ & $90.28 b(1.57)$ \\
\hline $\mathrm{PHBv/EFB/NPKC1}$ & 0 & 55.76a (7.08) & 79.57ab (7.37) & 89.31ab (1.28) & $96.48 \mathrm{a}(1.35)$ \\
\hline PHBv/EFB/NPKC2 & 0 & $58.66 a(7.47)$ & $88.41 \mathrm{a}(0.51)$ & $96.43 \mathrm{a}(0.57)$ & $99.35 \mathrm{a}(0.17)$ \\
\hline
\end{tabular}

Note: means of weight loss for the weight loss labelled with the same letters (a, ab, b, c, and d) were not significantly different at $P<0.05$. Standard deviation is given in parentheses. PHBv (poly(hydroxybutyrate-co-valerate)), NPKC1 (uncoated) and NPKC2 (coated), and EFB (empty fruit bunch), 5 replications of samples.

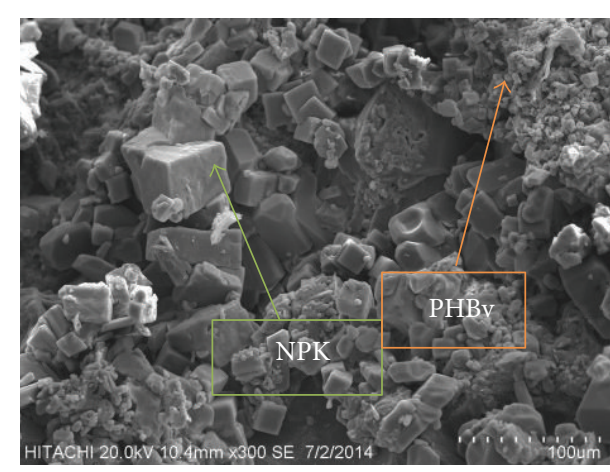

(a)

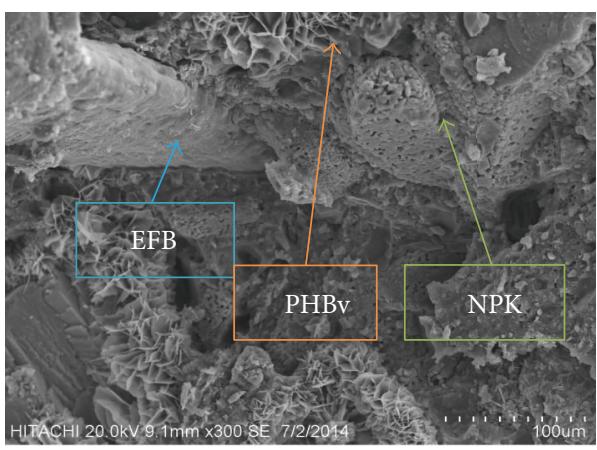

(c)

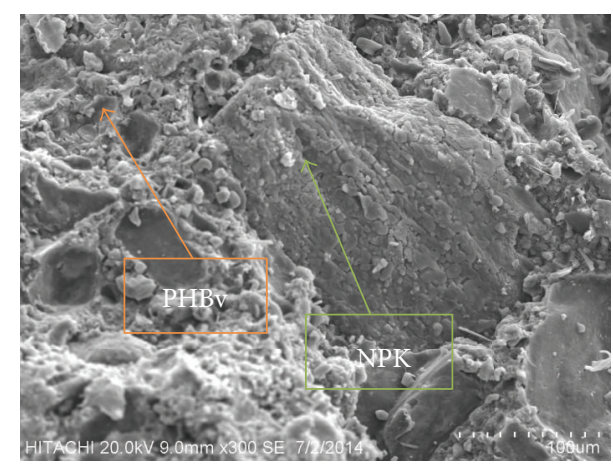

(b)

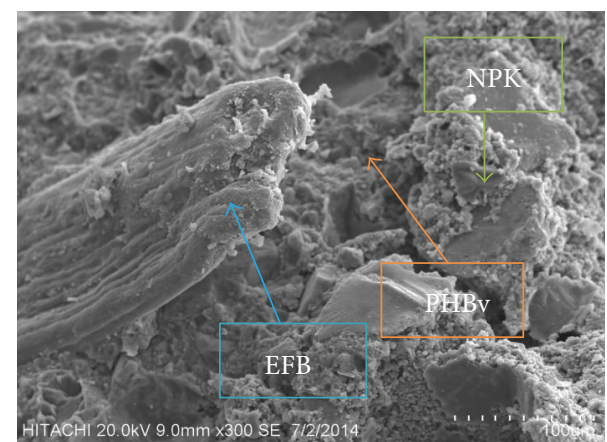

(d)

Figure 4: SEM of bioplastic fertilizer (BpF) composites. (a) PHBv/NPKC1, (b) PHBv/NPKC2, (c) PHBv/EFB/NPKC1, and (d) PHBv/EFB/ NPKC2. Note: PHBv (poly(hydroxybutyrate-co-valerate)), NPKC1 (uncoated) and NPKC2 (coated), and EFB (empty fruit bunch).

matrix and EFB fibers. This could be observed in the SEM images of the compounding fractured surfaces, as shown in Figure 4(c) PHBv/EFB/NPKC1 and (d) PHBv/EFB/NPKC2. $\mathrm{Bad}$ interfacial adhesion caused led to total debonding of the fibers from the matrix. As shown in Figure 4(c) PHBv/EFB/ $\mathrm{NPKC1}$, the EFB fiber protruded from the fractured $\mathrm{PHBv}$ composite surfaces. For $\mathrm{PHBv} / \mathrm{EFB} / \mathrm{NPK}$ composite, it was clear that weak interfacial adhesion manifested between the small gaps of the fibers and the matrix. Figure 4(d) PHBv/ EFB/NPKC2, also showed that the same situation occurred in the other PHBv composite. It has been discussed that the differences in polarity between PHBv and EFB fibers caused them to have low compatibility with each other, which led to the weak bonding.
3.5. Biodegradation of Bioplastic Fertilizer (BpF) Composites. The results from ANOVA analysis, Table 4, and Figure 5 show that the degradation rates of $\mathrm{BpF}$ composites were not significantly different, which was at $P<0.05$. Table 4 shows the rate of biodegradation composite samples. From the results, $\mathrm{PHBv} / \mathrm{EFB} / \mathrm{NPK}$ composites showed highest weight loss or greatest biodegradation along the study. The first stage of biodegradation involved the microbial attack on the surface of the polymer. An increase in water absorption enhanced the hydrolysis of ester groups on the PHB backbone [37]. The water absorption also caused debonding and enhanced dispersion of EFB fibers. Consequently, all of these led to more surface area exposed to microbial degradation, further increasing the biodegradation rate. 


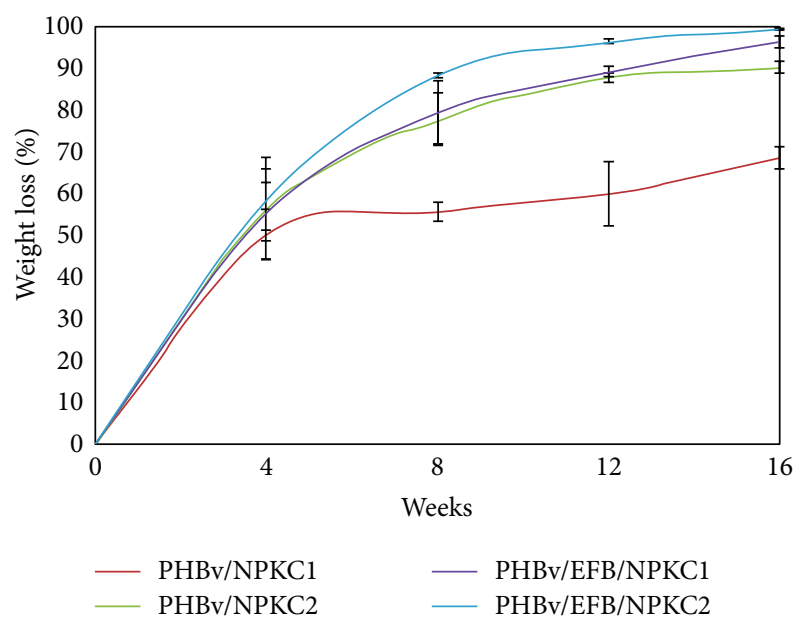

Figure 5: Mean of standard deviation and weight loss of PHBv/NPK and $\mathrm{PHBv} / \mathrm{EFB} / \mathrm{NPK}$ composites in soil burial test. Note: PHBv (poly(hydroxybutyrate-co-valerate)), NPKC1 (uncoated) and NPKC2 (coated), and EFB (empty fruit bunch), 5 replications of samples.

The biodegradation rate of polymers is influenced by multiple factors such as microbial activity, surface area, moisture, temperature, $\mathrm{pH}$, and nutrients. However, $\mathrm{PHBv}$ is not affected by moisture and also not soluble in water. It is stable for an indefinite period in air and no degradation should occur under normal storage conditions. In anaerobic conditions, the PHA degradation produces water, $\mathrm{CO}_{2}$, and methane $\left(\mathrm{CH}_{4}\right)$ while only water and $\mathrm{CO}_{2}$ are produced in aerobic conditions. The extent of polymer biodegradability is mainly determined by its chemical and physical properties. PHAs with high molecular weight are more resistant to biodegradation. In studying polymer biodegradability, it is also important to consider the melting temperature of the polymer.

Figure 5 depicts some of the samples that underwent the soil burial test for 4, 8, and 16 weeks. Significant degradation could be observed between Weeks 8 and 16. Most of the polymers biocomposites have degraded starting from Week 4, though PHBv/NPKC1 and PHBv/NPKC2 still kept some of their original shapes. The percentages of total weight loss for all samples are shown in Table 4. PHBv/EFB/NPKC2 (99.35\%) degraded better than PHBv/NPKC1 (68.66\%) and PHBv/NPKC2 (90.28\%) and had 30\% higher weight loss compared with $\mathrm{PHBv} / \mathrm{NPK}$. The test was halted after 16 weeks because it was no longer possible to accurately measure the weight loss beyond that point. The samples lacked structural integrity and seemed to be a mass of EFB fibers with many of the components already degraded.

Figure 6 shows the evidence from morphological images. The bonding of all composites created small gaps between matrices polymer and fiber because hydrophilic characteristic of the EFB fiber weakened the interfacial bonding. This gave advantage to the fiber in $\mathrm{BpF}$ to be degraded faster than PHBv composites. EFB fiber also absorbed water, degraded slowly, and swelled, allowing the release of fertilizer into soil. Furthermore, the presence of EFB fibers increased

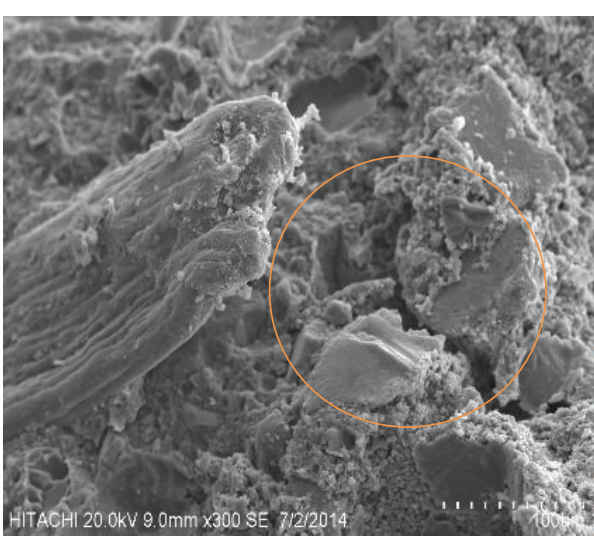

(a)

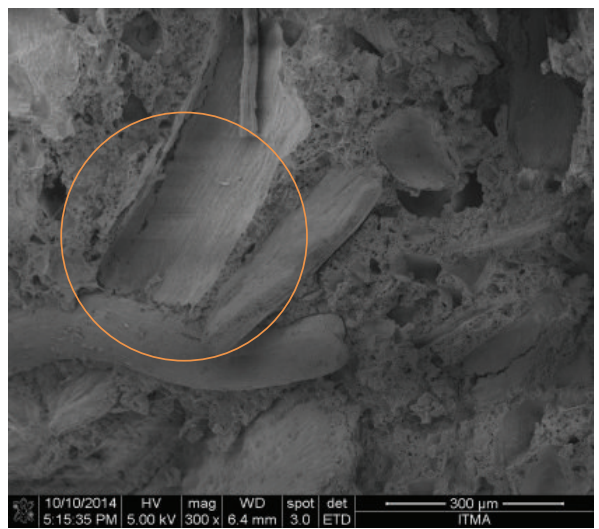

(b)

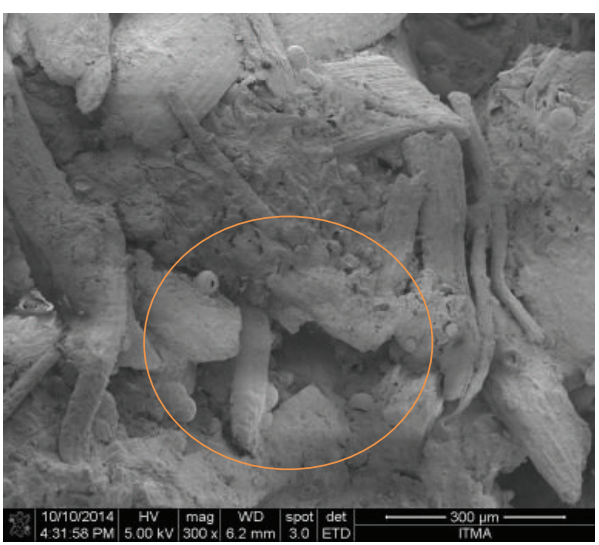

(c)

FIgURE 6: SEM micrographs of the soil burial samples. (a) PHBv/ EFB/NPKC2, 0 weeks, (b) PHBv/EFB/NPKC2, 8 weeks, and (c) $\mathrm{PHBv} / \mathrm{EFB} / \mathrm{NPKC} 2,16$ weeks. Note: PHBv (poly(hydroxybutyrateco-valerate)), NPKC2 (coated), and EFB (empty fruit bunch).

the surface area for the biodegradation of the composites. Figure 6(a) shows that the presence of EFB fibers in the composites enhanced biodegradation process, as indicated by the increase in the weight loss percentages of the samples. Figure 6(b) also shows that the PHBv/EFB/NPK biocomposites underwent more degradation after 8 weeks of soil burial test. It was assumed that the enhanced degradation of 
the composites was caused by the weak adhesion between the interface of PHBv matrix and EFB fibers. Figure 6(c) shows the complete detachment of components in PHBv/EFB/NPK biocomposites after 16 weeks. The formation of larger gaps due to detachment allowed more access for the microbes to reach the internal parts of the biocomposites, hence the enhanced biodegradation.

\section{Conclusions}

The $\mathrm{PHBv} / \mathrm{EFB} / \mathrm{NPKC} 2$ composite was more stable than pure $\mathrm{PHBv}$ because the former had a higher maximum degradation peak and it required higher initial degradation temperature. The PHBv composite degradability was improved by the addition of EFB fibers which increased the hydrophilicity of the composites. $\mathrm{PHBv} / \mathrm{NPKC} 1$ and $\mathrm{PHBv} / \mathrm{NPKC} 2$ reinforced with $10 \mathrm{wt} . \%$ EFB fiber were degraded faster in soil burial test. SEM results showed that the $\mathrm{PHBv} / \mathrm{NPKC1}$ and $\mathrm{PHBv} /$ NPKC2 composites without EFB fibers had better dispersion, wetting, and interfacial adhesion, hence the lower rate of biodegradation.

\section{Conflict of Interests}

The authors declare that there is no conflict of interests regarding the publication of this paper.

\section{Acknowledgment}

The paper was supported by Research Grant GP-IBT/2013/ 9420600/MST23 under Materials Science and Technology (MST) cluster supported by Research Management Centre, UPM.

\section{References}

[1] J. Zhang, S. McCarthy, and R. Whitehouse, "Reverse temperature injection molding of Biopol and effect on its properties," Journal of Applied Polymer Science, vol. 94, no. 2, pp. 483-491, 2004.

[2] G. J. M. de Koning and P. J. Lemstra, "Crystallization phenomena in bacterial poly $[(R)$-3-hydroxybutyrate]: 2. Embrittlement and rejuvenation," Polymer, vol. 34, no. 19, pp. 4089-4094, 1993.

[3] F. Biddlestone, A. Harris, J. N. Hay, and T. Hammond, "The physical ageing of amorphous poly(hydroxybutyrate)," Polymer International, vol. 39, no. 3, pp. 221-229, 1996.

[4] M. Scandola, G. Ceccorulli, and M. Pizzoli, "Miscibility of bacterial poly(3-hydroxybutyrate) with cellulose esters," Macromolecules, vol. 25, no. 24, pp. 6441-6446, 1992.

[5] D. O. Huett and B. J. Gogel, "Longevities and nitrogen, phosphorus, and potassium release patterns of polymer-coated controlled-release fertilizers at $30^{\circ} \mathrm{C}$ and $40^{\circ} \mathrm{C}$," Communications in Soil Science and Plant Analysis, vol. 31, no. 7-8, pp. 959973, 2000.

[6] C.-S. Wu, "Controlled release evaluation of bacterial fertilizer using polymer composites as matrix," Journal of Controlled Release, vol. 132, no. 1, pp. 42-48, 2008.

[7] M. K. Hafshejani, F. Khandani, R. Heidarpour, A. Arad, and S. Choopani, "Study the sources of mercury vapor in atmosphere as a threatening factor for human health and bio-filtering methods for removal of toxic pollution," Life Science Journal, vol. 10, no. 1, pp. 293-296, 2013.

[8] A. M. Dave, M. H. Mehta, T. M. Aminabhavi, A. R. Kulkarni, and K. S. Soppimath, "A review on controlled release of nitrogen fertilizers through polymeric membrane devices," PolymerPlastics Technology and Engineering, vol. 38, no. 4, pp. 675-711, 1999.

[9] A. Shaviv, "Advances in controlled-release fertilizers," in Advances in Agronomy, vol. 71, pp. 1-49, Academic Press, New York, NY, USA, 2001.

[10] Sh. Jin, G. Yue, L. Feng, Y. Han, X. Yu, and Z. Zhang, "Preparation and properties of a coated slow-release and waterretention biuret phosphoramide fertilizer with superabsorbent," Journal of Agricultural and Food Chemistry, vol. 59, no. 1, pp. 322-327, 2011.

[11] S. K. Jain, 2007, http://www.Pharmainfo.net.

[12] I. Bhattacharya, S. Bandyopadhyay, Ch. Varadachari, and K. Ghosh, "Development of a novel slow-releasing ironmanganese fertilizer compound," Industrial and Engineering Chemistry Research, vol. 46, no. 9, pp. 2870-2876, 2007.

[13] F. Munoz, R. S. Mylavarapu, and C. M. Hutchinson, "Environmentally responsible potato production systems: a review," Journal of Plant Nutrition, vol. 28, no. 8, pp. 1287-1309, 2005.

[14] Z. Cong, S. Yazhen, D. Changwen, Z. Jianmin, W. Huoyan, and C. Xiaoqin, "Evaluation of waterborne coating for controlledrelease fertilizer using Wurster fluidized bed," Industrial and Engineering Chemistry Research, vol. 49, no. 20, pp. 9644-9647, 2010.

[15] M. Tomaszewsa and A. Jarosiewicz, "Polysulfone coating with starch addition in CRF formulation," Desalination, vol. 163, no. 1-3, pp. 247-252, 2004.

[16] A. S. Mathews and S. Narine, "Poly[ $N$-isopropyl acrylamide]co-poryurethane copolymers for controlled release of urea," Journal of Polymer Science, Part A: Polymer Chemistry, vol. 48, no. 15, pp. 3236-3243, 2010.

[17] Z. Peng and F. Chen, "Synthesis and properties of lignin-based polyurethane hydrogels," Journal of Polymer Materials, vol. 60, no. 9, pp. 674-683, 2011.

[18] Z. Y. Peng and F. G. Chen, "Synthesis and properties of temperature-sensitive hydrogel based on hydroxyethyl cellulose," International Journal of Polymeric Materials and Polymeric Biomaterials, vol. 59, no. 6, pp. 450-461, 2010.

[19] G. E. Ibrahim, A. F. Abdel-Motaleb, and E. R. E. Mahmoud, "Achieving optimum scientific standards for producing fabrics suitable for protecting against hazardous chemical liquids," Life Science Journal, vol. 10, no. 1, pp. 342-353, 2013.

[20] A. K. Bledzki and J. Gassan, "Composites reinforced with cellulose based fibres," Progress in Polymer Science, vol. 24, no. 2, pp. 221-274, 1999.

[21] B.-J. Kim, F. Yao, G. Han, and Q. Wu, "Performance of bamboo plastic composites with hybrid bamboo and precipitated calcium carbonate fillers," Polymer Composites, vol. 33, no. 1, pp. 68-78, 2012

[22] G. M. Blouin, D. W. Rindt, and O. E. Moore, "Sulfur-coated fertilizers for controlled release. Pilot-plant production," Journal of Agricultural and Food Chemistry, vol. 19, no. 1, p. 80, 1971.

[23] A. Meisen and K. B. Mathur, "Characteristic dimension and shape factor of particles," Proceedings of the British Sulphur 20 Corporation, vol. 2, 1978. 
[24] O. A. Salman, "Polymer coating on urea prills to reduce dissolution rate," Journal of Agricultural and Food Chemistry, vol. 36, no. 3, pp. 616-621, 1988.

[25] C. H. Wu, "Controlled release evaluation of bacterial fertilizer using polymer composites as matrix," Journal of Controlled Released, vol. 132, no. 1, pp. 42-48, 2008.

[26] M. Tzika, S. Alexandridou, and C. Kiparissides, "Evaluation of the morphological and release characteristics of coated fertilizer granules produced in a Wurster fluidized bed," Powder Technology, vol. 132, no. 1, pp. 16-24, 2003.

[27] M. Devassine, F. Henry, P. Guerin, and X. Briand, "Coating of fertilizers by degradable polymers," International Journal of Pharmaceutics, vol. 242, no. 1-2, pp. 399-404, 2002.

[28] S. Tao, J. Liu, K. Jin et al., "Preparation and characterization of triple polymer-coated controlled-release urea with waterretention property and enhanced durability," Journal of Applied Polymer Science, vol. 120, no. 4, pp. 2103-2111, 2011.

[29] S. Mishra, S. Tripathy, M. Mishra, A. K. Mohanty, and S. Nayak, "Novel eco-friendly biocomposites: biofiber reinforced biodegradable polyester amide composites-fabrication and properties evaluation," Journal of Reinforced Plastics and Composites, vol. 21, no. 1, pp. 55-70, 2002.

[30] K. Oksman, M. Skrifvars, and J.-F. Selin, "Natural fibres as reinforcement in polylactic acid (PLA) composites," Composites Science and Technology, vol. 63, no. 9, pp. 1317-1324, 2003.

[31] S. Lee, D. Cho, W. Park, S. Han, and L. Drzal, "Novel silk/poly(butylene succinate) biocomposites: the effect of short fibre content on their mechanical and thermal properties," Composites Science and Technology, vol. 65, no. 3-4, pp. 647-657, 2005.

[32] A. Paul and S. Thomas, "Electrical properties of natural-fiberreinforced low density polyethylene composites: a comparison with carbon black and glass-fiber-filled low density polyethylene composites," Journal of Applied Polymer Science, vol. 63, no. 2, pp. 247-266, 1997.

[33] J. M. Felix and P. Gatenholm, "Nature of adhesion in composites of modified cellulose fibers and polypropylene," Journal of Applied Polymer Science, vol. 42, no. 3, pp. 609-620, 1991.

[34] G. Williams and R. Wool, "Composites from natural fibers and soy oil resins," Applied Composite Materials, vol. 7, no. 5, pp. 421432, 2000.

[35] K. Oksman and J.-F. Selin, "Plastics and composites from polylactic acid," in Natural Fibers, Plastics and Composites, F. T. Wallenberger and N. E. Weston, Eds., pp. 149-165, Kluwer Academic, Dordrecht, Netherlands, 2004.

[36] S. Luo and A. Netravali, "Characterization of henequen fibers and the henequen fiber/poly(hydroxybutyrate-co-hydroxyvalerate) interface," Journal of Adhesion Science and Technology, vol. 15, no. 4, pp. 423-437, 2001.

[37] Q.-S. Liu, M.-F. Zhu, W.-H. Wu, and Z.-Y. Qin, "Reducing the formation of six-membered ring ester during thermal degradation of biodegradable PHBV to enhance its thermal stability," Polymer Degradation and Stability, vol. 94, no. 1, pp. 18-24, 2009.

[38] S. Nguyen, G.-E. Yu, and R. H. Marchessault, “Thermal degradation of poly(3-hydroxyalkanoates): preparation of welldefined oligomers," Biomacromolecules, vol. 3, no. 1, pp. 219-224, 2002.

[39] A. Javadi, Y. Srithep, S. Pilla, J. Lee, S. Gong, and L.-S. Turng, "Processing and characterization of solid and microcellular $\mathrm{PHBV/coir} \mathrm{fiber} \mathrm{composites,"} \mathrm{Materials} \mathrm{Science} \mathrm{and} \mathrm{Engineering}$ C, vol. 30, no. 5, pp. 749-757, 2010.
[40] C. Eldsäter, B. Erlandsson, R. Renstad, A.-C. Albertsson, and S. Karlsson, "The biodegradation of amorphous and crystalline regions in film-blown poly(e-caprolactone)," Polymer, vol. 41, no. 4, pp. 1297-1304, 2000. 

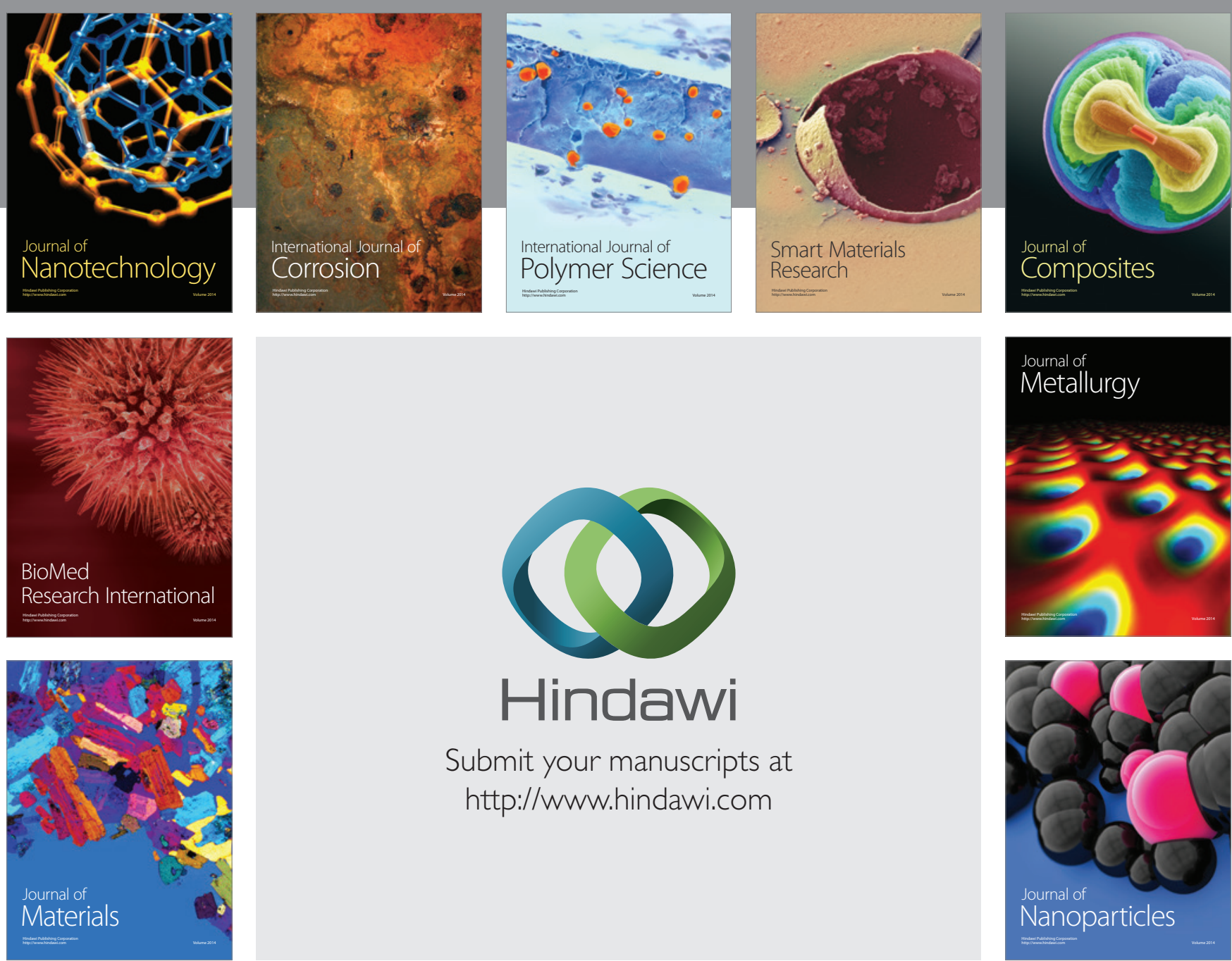

\section{Hindawi}

Submit your manuscripts at

http://www.hindawi.com

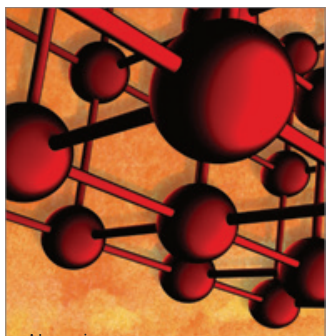

Materials Science and Engineering
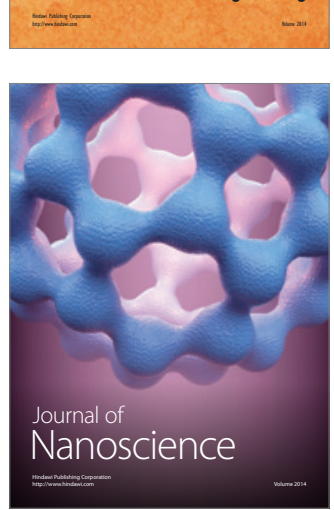
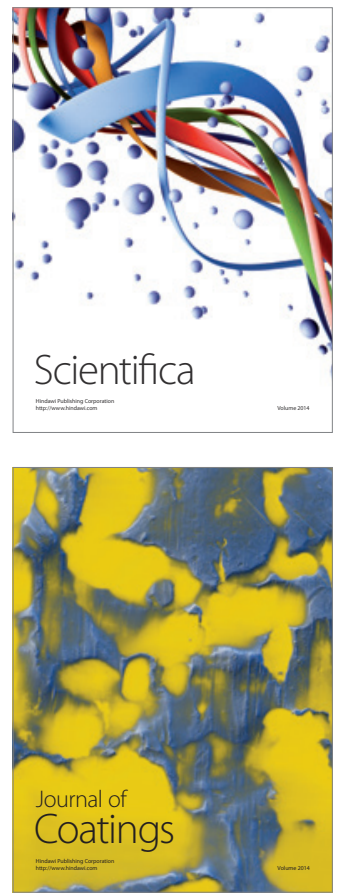
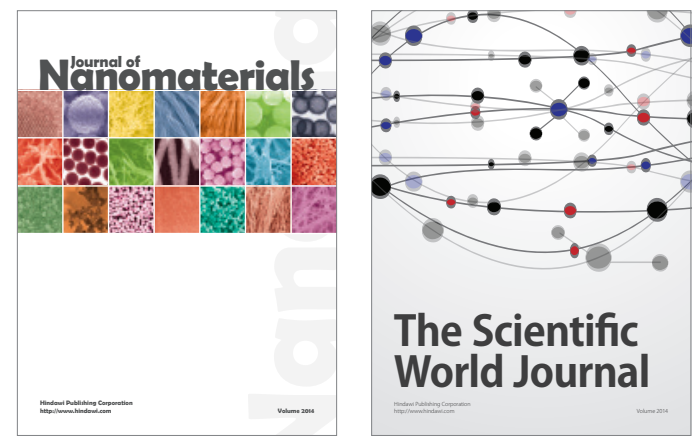

The Scientific World Journal
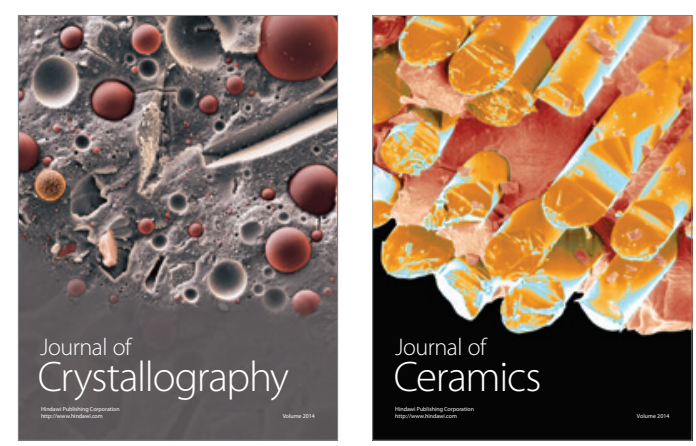
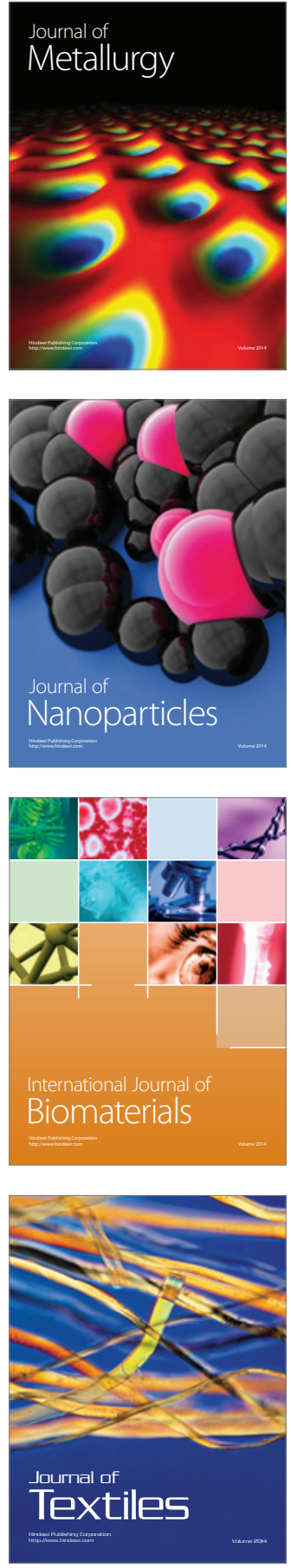